\title{
Novitates
}

PUBLISHED BY THE AMERICAN MUSEUM OF NATURAL HISTORY CENTRAL PARK WEST AT 79TH STREET, NEW YORK, NY 10024

Number 3494, 17 pp., 10 figures, 1 table November 29, 2005

\section{New Avian Remains from the Eocene of Mongolia and the Phylogenetic Position of the Eogruidae (Aves, Gruoidea)}

\author{
JULIA A. CLARKE, ${ }^{1}$ MARK A. NORELL, ${ }^{2}$ \\ AND DEMBERELYIN DASHZEVEG ${ }^{3}$
}

\begin{abstract}
A well-preserved nearly complete avian tarsometatarsus was collected by the 2002 expedition of the Mongolian Academy of Sciences from upper Eocene deposits exposed at the locality of Alag Tsav in the Eastern Gobi desert (Dornogov Aimag) of Mongolia. The new specimen is identified as part of a proposed Eogruidae clade, although it is unclear whether it is appropriately the holotype of a new species within this clade or referable to a previously named species. The clade Eogruidae has, as its current contents, species named as part of the traditional families Eogruidae + Ergilornithidae, which include several taxa of completely didactylous and apparently flightless birds. Referral of the new fossil to the clade Eogruidae is on the basis of derived reduction/loss of the metatarsal II trochlea.

A series of phylogenetic analyses was used to investigate the systematic position of Eogruidae (including the new fossil, IGM 100/1447), which have been proposed to be a dominant part of Eocene to Miocene Asian faunas. First, the Mayr and Clarke (2003) dataset for crown clade Aves was used to investigate placement of Eogruidae within Aves, using a more completely known eogruid, Eogrus aeola, as an exemplar taxon. Eogrus aeola was identical to the new tarsometatarsus for all scored characters. A strict consensus cladogram of three most parsimonious trees from 1000 replicate heuristic searches placed Eogrus aeola in an unresolved polytomy with Psophiidae and Gruidae (Trumpeters and Cranes).
\end{abstract}

\footnotetext{
${ }^{1}$ North Carolina State University, Department of Marine, Earth, and Atmospheric Sciences, Campus Box 8208, Raleigh, NC 27695-8208 and North Carolina Museum of Natural Sciences (Julia_Clarke@ncsu.edu); Division of Paleontology, American Museum of Natural History.

${ }^{2}$ Division of Paleontology, American Museum of Natural History (norell@amnh.org).

${ }^{3}$ Division of Paleontology, American Museum of Natural History; Geological Institute of the Mongolian Academy of Sciences, Ulaan Baatar, Mongolia.
} 
Given the results of this analysis, Eogruidae (including IGM 100/1447) was analyzed in the suborder Grues dataset of Livezey (1998). Eogruidae was placed as the sister taxon to an Aramidae + Gruidae clade in the strict consensus cladogram of the eight most parsimonious trees resulting from a branch and bound search. Because monophyly of the traditional order Gruiformes has been repeatedly questioned, and the outgroups used in the original Grues dataset were identified through analyses assuming monophyly, the impact of removing these assumptions was investigated. Placement was robust to both changing outgroup assumptions and to swapping in the more incompletely known IGM 100/1447 as an exemplar for Eogruidae.

\section{INTRODUCTION}

New fossil remains, including that described here, were collected in 2002 from upper Eocene deposits exposed at the locality of Alag Tsav in the eastern Gobi desert (Dornogov Aimag) of Mongolia (fig. 1) by an expedition of the Mongolian Academy of Sciences led by D. Dashzeveg. Alag Tsav (alternative spelling: Alag Tsab, Dashzeveg, $1996 \mathrm{a}, 1996 \mathrm{~b})$ is located close to the Chinese border just southeast of the well-known $\mathrm{Pa}-$ leogene Ergilin-Dzo locality and 30 kilometers south of the center of Ulaan Badrakh Sum (Dashzeveg, 1985; Russell and Zhai, 1987). The approximate coordinates of the locality were previously given as latitutde $38^{\circ} 29^{\prime} \mathrm{N}$; longitude $125^{\circ} 49^{\prime} \mathrm{E}$; (Russell and
Zhai, 1987). However, the location of the Alag Tsav indicated in the present paper (fig. 1) is significantly different from this earlier work and is considered more accurate (Dashzeveg, personal commun.). Alag Tsav was discovered by D. Dashzeveg in 1982 (Dashzeveg, 1985).

A well-preserved, nearly complete avian tarsometatarsus (IGM 100/1447; fig. 2) was found in a light grey sandstone in the main exposures of Alag Tsav, where it was associated with remains of Ardynomys russelli (Dashzeveg, 1996a). In addition to Ardynomys russelli (Cylindrodontidae), Hyaenodon (Hyaenodontidae), Gigantamynodon (Amynodontidae), Stenoplesictis (Viverridae), Teleolophus (Deperetellidae), and the basal ru-

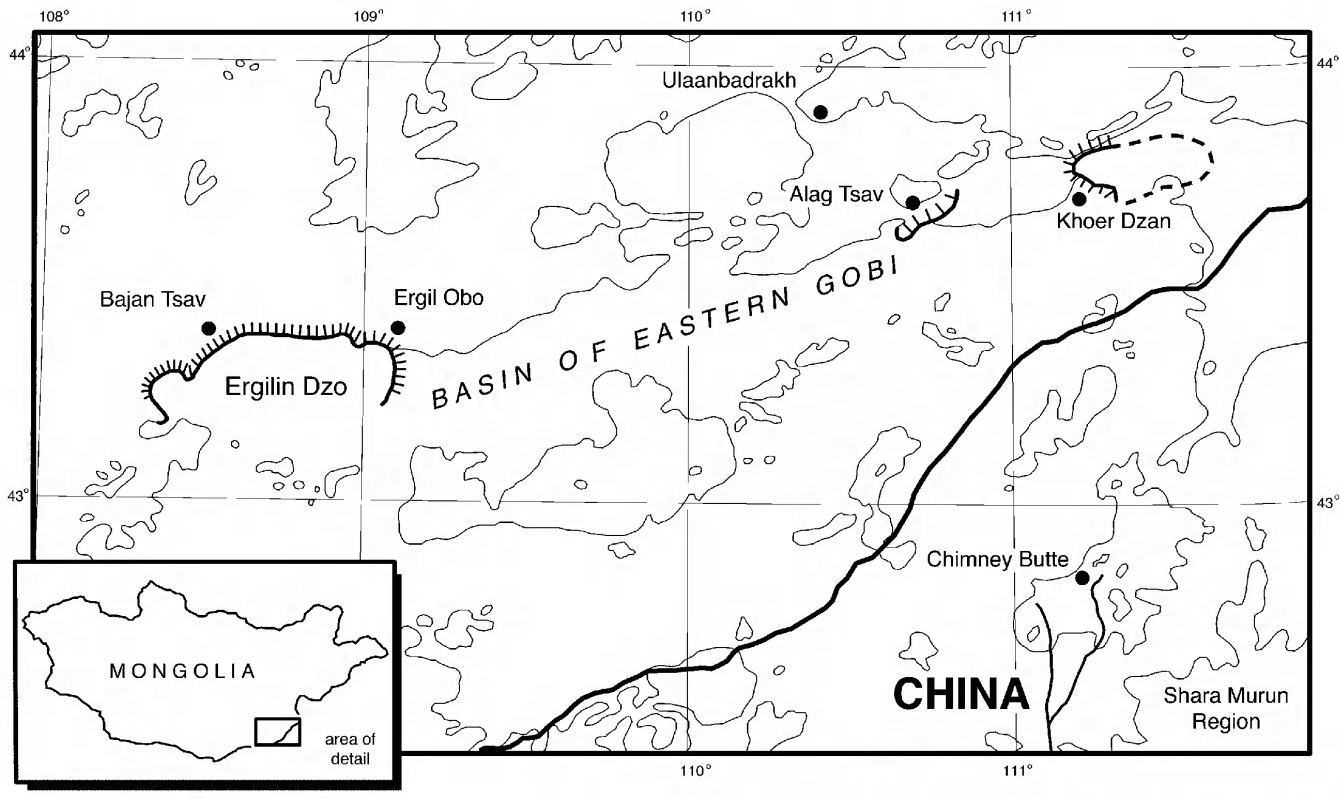

Fig. 1. Map of the Paleogene bird localities in the eastern Gobi Desert, Mongolia, including Alag Tsav, where the new fossil was recovered. 


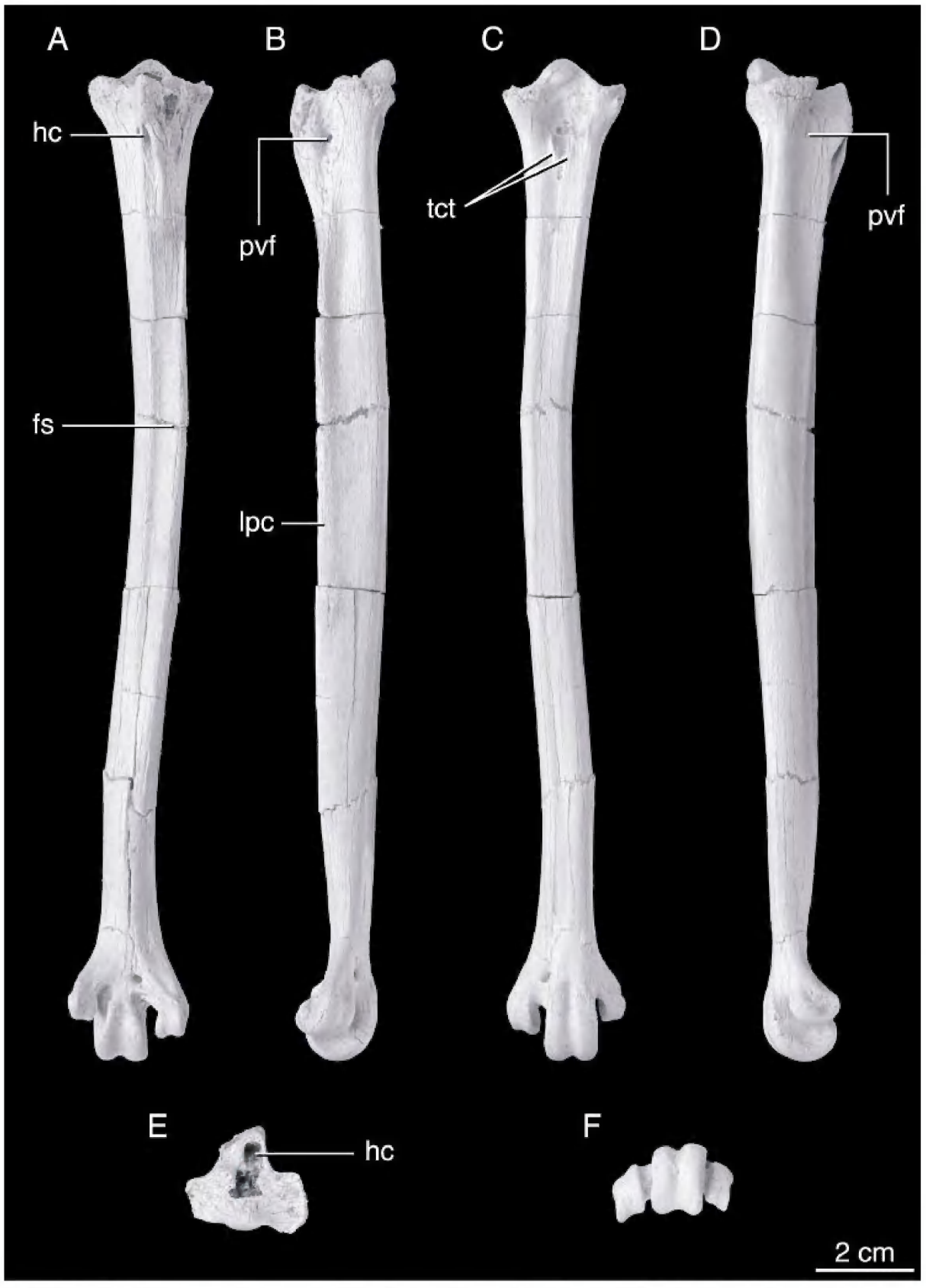

Fig. 2. The right tarsometatarsus IGM 100/1447 in (A) plantar, (B) lateral, (C) dorsal, (D) medial, (E) proximal and (F) distal views. Anatomical abbreviations: he hypotarsal canal, fs flexor sulcus, lpc lateral plantar crest, pvf proximal vascular foramen, tct $\mathrm{m}$. tibialis cranialis tubercles. 
minant Archaeomeryx are also known from these deposits (Dashzeveg, 1985, 1996b; Russell and Zhai, 1987). The Sevkhul Member (Ergilin Dzo Formation) has been correlated with deposits overlying the avian fossil bearing unit at Alag Tsav (Dashzeveg, 1996b: fig. 1). Therefore, this unit must be older than the fossil-bearing units at the classic eastern Gobi localities of Ergilin Dzo and Khoer Dzan (fig. 1), where the Sevkhul and overlying Ergilin Members of the Ergilin Dzo Formation (Russell and Zhai, 1987) are exposed.

The boundary between the Eocene and Oligocene in the section at Ergilin Dzo and Khoer Dzan has been interpreted to lie below the Ergilin Member (Ergilin Dzo Formation; Dashzeveg, 1996b). It is in the Ergilin Member that early Oligocene genera of mammals are first observed (e.g., Bothriodon, Entelodon, Ronzotherium; Dashzeveg 1996b; Russell and Zhai, 1987). The relationship of this boundary to intercontinental faunal correlations and the Eocene/Oligocene boundary in Europe and North America has been extensively discussed in Dashzeveg and Devyatkin (1986) and Dashzeveg (1993, 1996b). Furthermore, based on comparisons with wellknown faunas from deposits in Inner Mongolia, China, the exposures at Alag Tsav are interpreted as contemporaneous with the Shara Murun Formation exposed at Ulan Usu (Dashzeveg, 1985, 1991), assessed to be late Eocene in age (Russell and Zhai, 1987). Alag Tsav is one of the few localities in Mongolia interpreted to represent this part of the Eocene (Russell and Zhai, 1987).

Avian fossils are comparatively abundant from the Late Eocene and Early Oligocene of the eastern Gobi Desert, where they have been recovered primarily from Khor Dzan and Ergilin Dzo in Mongolia and from the Shara Murun region of Inner Mongolia, China (fig. 1). The majority of these remains have been identified as part of a radiation of crane-like, cursorial birds and placed in either the Eogruidae or the Ergilornithidae families (Wetmore, 1934; Kozlova, 1960; Kurochkin, 1976, 1981, 1982). Nearly all of these remains are distal pelvic limb elements: tibiotarsi and tarsometatarsi (Wetmore, 1934; Kozlova, 1960; Kurochkin, 1976, 1981, 1982) although a coracoid, a proximal humerus, as well as manual phalanges I: 1 and
II:1 have also been identified (Wetmore, 1934; Kurochkin, 1976, 1981).

Wetmore (1934) originally named the family Eogruidae for the species Eogrus aeola. All of the remains that he referred to this species, and including those illustrated in this paper (figs. 3-7, 8B), were from localities in the Shara Murun region, China (fig. 1), and from deposits assessed to be middle Eocene in age (Ulan Shireh/Irdin Manha Formations; Russell and Zhai, 1987). These localities include Chimney Butte, Camp Margetts, (e.g., AMNH 2946; figs. 6B, 7) and sublocalities southwest of Iren Dabasu. One specimen (AMNH 2947) was collected north of Arshanto Obo (Wetmore, 1934) and is also of middle Eocene age (Russell and Zhai, 1987) but from the Arshanto Formation (Radinsky, 1964).

Wetmore (1934) also discussed material identified as Eogrus sp. collected in Mongolia near "Ardyn Obo" (i.e., Ergil Obo = sublocality of Ergilin Dzo, Ergilin Member, Ergilin Dzo Formation; early Oligocene, Russell and Zhai, 1987; fig. 1, this paper) and the Tunggur Formation exposed near Wolf Camp 40 miles southeast of Iren Dabasu, Shara Murun region (middle Miocene; Wang et al., 2003). One of these specimens (AMNH 2949; fig. 8A), from the Tunggur Formation, originally considered to be from a distinct taxon closely allied with Eogrus aeola if not part of the same species (Wetmore, 1934: 12), was later indicated as the holotype specimen of a new species. This species, Eogrus wetmorei, named in a footnote in Brodkorb (1967), was diagnosed by its being slightly smaller than Eogrus aeola. Subsequently, three additional species were named and placed in the Eogruidae: Eogrus crudus (Kurochkin, 1981) from middle upper Eocene at Tsagan Khutel, central Mongolia (Russell and Zhai, 1987); Eogrus turanicus (Bendukidze, 1971) from middle-upper Eocene near the Kalmakpai River, Kazakhstan; and Sonogrus gregalis (Kurochkin, 1981) from the upper Eocene-lower Oligocene exposed at Khor Dzan (Sevkhul Member, Ergilin Dzo Formation).

Eogrus was placed in its own subfamily Eogruinae within the traditional suborder of Gruiformes, Grues, and the family Gruidae by Brodkorb (1967). Ergilornis, named by Ko- 
zlova in 1960 , was placed within a separate family within Grues, Ergilornithidae, which also includes the completely didactylous Miocene Amphipelargus (= Urmiornis, Harrison, 1981, though see Karhu, 1997). In sum, five species of Eogruidae and seven of Ergilornithidae (sensu Brodkorb, 1967) have been identified (reviewed in Kurochkin, 1981 and Karhu, 1997). Stratigraphy seems to have been taken into consideration in the identification of subsequent eogruid species. For example, it is doubtful that Eogrus wetmorei would have been diagnosed as a distinct species (Brodkorb, 1967) were it not for its middle Miocene age (Cracraft, 1973) especially since its diagnosis as smaller than that of Eogrus aeola (Brodkorb, 1967) does not hold, given the size range of specimens referred to Eogrus aeola (e.g., AMNH 2946; fig. 8).

Wetmore (1934) considered eogruids closely related to Gruidae (Cranes). Cracraft (1969) mentioned a clade including Eogruidae, Gruidae, Aramidae (Limpkin), and Psophiidae (Trumpeters) as supported, and later figured (Cracraft, 1973: fig. 46) an Ergilornithidae + Eogruidae clade as the sister taxon to a Gruidae, Aramidae + Psophiidae clade (i.e., Cranes sister taxon of a Limpkin + Trumpeters clade). Gruidae was placed as the sister taxon of Aramidae with alternatively Psophiidae (Livezey, 1998) or a Psophiidae + Opisthicomidae clade (Livezey and Zusi, 2001) as its immediate outgroup. More recently a Gruidae + Aramidae clade with Psophiidae as its sister taxon was also recovered from molecular data (e.g., Cracraft et al., 2004; Fain and Houde, 2004). A Psophiidae + Gruidae clade was also recovered with bootstrap support (Aramidae was not included) in Mayr and Clarke (2003).

Institutional Abbreviations: AMNH American Museum of Natural History, New York; IGM Institute of Geology, Mongolian Academy of Sciences, Ulaan Baatar; PIN Paleontological Institute of the Russian Academy of Sciences, Moscow.

\section{SYSTEMATIC PALEONTOLOGY AVES LINNAEUS, 1758 \\ GRUES BONAPARTE, 1854 \\ GRUOIDEA VIGORS, 1825 \\ EOGRUIDAE WETMORE, 1934}

The original diagnosis of the family Eogruidae (Wetmore 1934: 3) was "related to Gruidae but with lateral trochlea of metatarsus reduced and simplified in form, the leg and foot being modified for running, legs long and slender ...". Modification for running was inferred to be manifest in the conformation of the distal tarsometatarsus including, "robustness" of the metatarsal III trochlea and reduction of the metatarsal II and IV trochleae (Wetmore, 1934: 11). Weak development of the wing on the medial plantar surface of metatarsal II, with eight other morphologies of the tarsometatarsus and tibiotarsus, was additionally identified to differentiate the single species of Eogruidae he named (Wetmore, 1934: 3-4). Cracraft (1973), in his extensive review of fossil Grues, revised the diagnosis of the Eogruidae to include not only the reduction of the metatarsal II and IV trochleae but also their lack of plantar deflection.

A more marked reduction in the metatarsal II trochlea relative to that observed in the new fossil and in species of the family Eogruidae is present in the traditional family Ergilornithidae (Cracraft, 1973; Kurochkin, 1976, 1981, 1982; Olson, 1985). Indeed, Ergilornithidae have been diagnosed by the reduction of metatarsal II trochlea to a "small stub" (e.g., Cracraft (1973: 73). Reduction of the metatarsal II trochlea is considered here to be diagnostic of a clade whose current contents include the species recognized as parts of these two traditional families (e.g., Brodkorb, 1967; Kurochkin, 1981; Karhu, 1997). Eogruidae is used as the name for this clade as it was the first higher taxon name proposed (Wetmore, 1934). Eogrus aeola (holotype specimen, AMNH 2936; Wetmore, 1934 ) is named as the internal specifier (sensu Cantino and de Queiroz, 2000) for the clade, as its first-named included species.

The contents of the traditional family Eogruidae may be paraphyletic with respect to Ergilornithidae. Indeed, Eogruidae was repeatedly suggested to be "ancestral" or to have given rise to Ergilornithidae (Cracraft, 1973; Kurochkin, 1976, 1981, 1982). The taxa included in the family Eogruidae were distinguished from Ergilornithidae by retention of the following plesiomorphic morphology for Grues (and for Aves generally): the presence of a comparatively less reduced 
metatarsal II trochlea (Cracraft, 1973; Kurochkin, 1976, 1981, 1982).

"Eogruidae" is recommended, but not defined, as an apomorphy-based name (de Queiroz and Gauthier, 1992) for the clade, including all taxa with a reduced, or lost, metatarsal II trochlea homologous with Eogrus aeola. The taxon Ergilornithidae is not revised or defined here. The name Ergilornithidae is used here to refer to contents specified by the last revisers of the taxon (Kurochkin, 1981; Karhu, 1997). These contents are considered part of the clade Eogruidae as the name is used in the current paper. It is clear that taxonomic conventions maintaining Ergilornithidae at the same rank as Eogruidae confound more than they clarify understanding about the evolution of this group.

Specimen IGM $100 / 1447$ is identical to Eogrus aeola for the morphologies represented by 24 cladistic characters from the Livezey (1998) dataset and 7 characters from the Mayr and Clarke (2003) dataset (i.e., those preserved and able to be evaluated in the new fossil; appendix 1). It is referred to Eogruidae on the basis of proposed autapomorphies of the distal tarsometatarsus approaching the morphologies referenced by previous diagnoses (e.g., Wetmore, 1934; Cracraft, 1973) and considered to diagnose an Eogruidae clade relative to other Grues (sensu Livezey, 1998). All of these apomorphies are of the metatarsal II trochlea and could describe the reduction in this trochlea noted previously (Wetmore, 1934; Cracraft, 1973). The description of these characters follows. The metatarsal II trochlea is proportionally narrower in Eogruidae. It lacks a medioplantar wing, a more extreme condition than seen in other Grues, and than those compassed by Livezey (1998: 2121, character 351:0). Additionally, the metatarsal II trochlea is slightly less plantarly projected than that of IV (figs. 2F, 6C). Weak plantar projection (the metatarsal II trochlea equal to that of IV in extent) is addressed by Livezey (1998: 2121, character 352: 0), however, the metatarsal II trochlea being less projected plantarly than IV is not compassed by the character states identified.

It is possible that IGM 100/1447 represents a new species (see further comments in the Discussion); however, it is here considered Eogruidae incertae sedis pending direct comparison with the other named eogruid species (e.g., Sonogrus gregalis; Kurochkin, 1981; see Discussion) and the discovery of relevant new material. If further reduction of the metatarsal II trochlea is found to diagnose an Ergilornithidae clade within the proposed Eogruidae clade, as appears supported, then IGM 100/1447 is outside of this Ergilornithidae clade.

\section{DESCRIPTION OF THE NEW SPECIMEN}

IGM $100 / 1447$ is a nearly complete right tarsometatarsus (fig. 2). It is from a species close in size to extant species of Gruidae including, for example, Balearica pavonina (Black-Crowned Crane; e.g., AMNH 10775). The tarsometatarsus of IGM 100/1447 is just slightly shorter than that of this species. A small portion of the lateroplantar surface of the hypotarsus and the intercotylar area are missing (fig. 2A, E). The intercotylar process is well projected and dorsally bulbous with a defined, curved dorsodistal margin (fig. $2 \mathrm{C})$. The dorsal openings of the proximal vascular foramina are subequal in size, adjacent, and set in a deep infracotylar fossa (fig. 2C). Their plantar exits are also subequal in size with the lateral placed just slightly distal to the medial (compare fig. 2B, D). Several additional smaller foramina are developed on the dorsal tarsometatarsal midline, proximal and distal to the paired foramina and to the well-projected tubercles of the m. tibialis cranialis, respectively (fig. 2C). The extensor retinaculum tubercles on the proximodorsal surface of metatarsal II are also well developed (fig. 2C).

The parahypotarsal fossae are shallow with the medial slightly deeper than the lateral. The medial fossa extends well distal to the hypotarsus. There is only one hypotarsal canal developed in the hypotarsus, which is medially located and is inferred to correspond to Canal I of Strauch (1978; fig. 2A, E). There is a smoothly angling lateral margin to the distal opening of this canal that continues into the distally extensive lateral hypotarsal ridge. This lateral hypotarsal crest extends farthest distally (fig. 2A), while the 


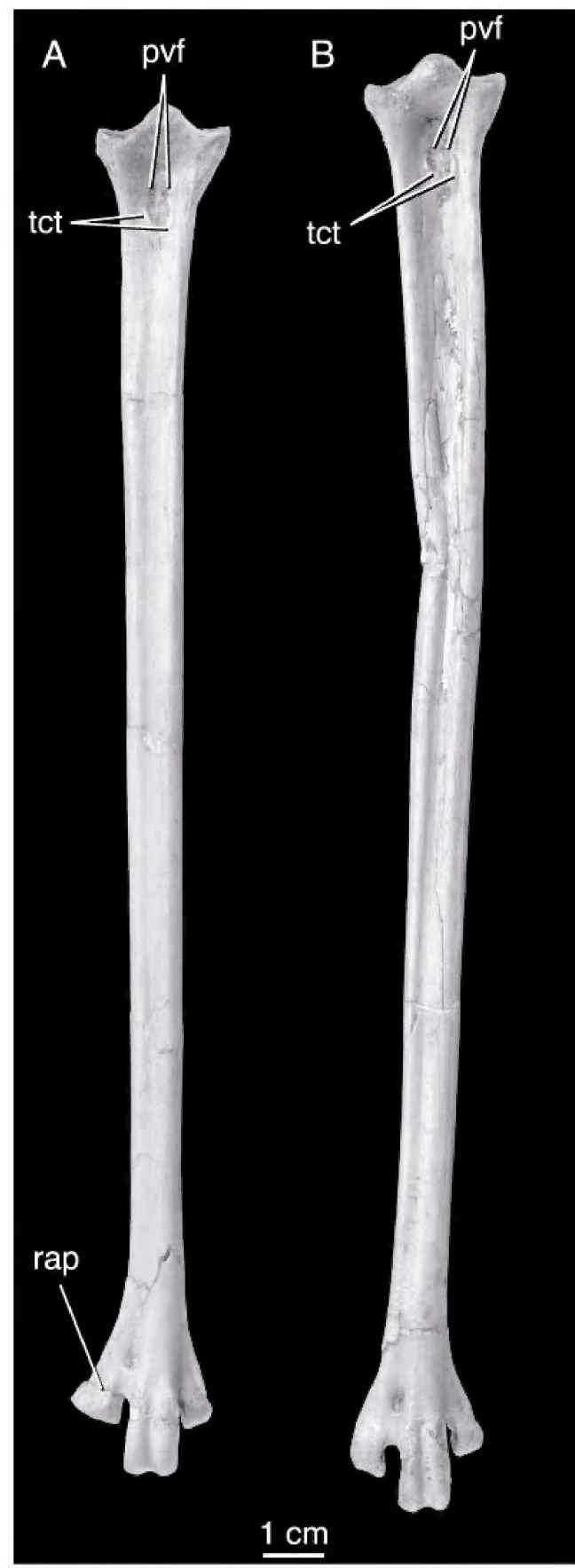

Fig. 3. Two right tarsometatarsi (in dorsal view) collected in 1928 from a quarry at the Chimney Butte locality, Shara Murun region, medial crest is projected farthest plantarly (fig. 2E). The two laterally developed, extremely superficial hypotarsal sulci in Eogrus aeola (Wetmore, 1934) may also have been present, but the bone surface in the new fossil is inadequately preserved to discern this with confidence.

The shaft of the tarsometatarsus is robust, with its proximal and distal ends notably broad for its length, especially when compared with the Eogrus aeola holotype and referred specimens (compare figs. 2, 3). The lateral plantar crest is very well projected, although its plantar projection appears slightly exaggerated by breakage (fig. 2A). The medial crest extends farther proximally than this lateral crest to reach the medial edge of the hypotarsus. It bounds one side of a comparatively pronounced flexor sulcus distally (fig. 2A).

The trochlea of metatarsal II is conspicuously narrower than that of metatarsal IV (fig. 2F) and is approximately one half the width of that of metatarsal III. The metatarsal III trochlea is proportionally broader than that of Eogrus aeola (compare figs. 2, 3). Neither the metatarsal II nor the metatarsal IV trochlea is significantly plantarly deflected, and both lack pronounced wings on their medial and lateral plantar edges, respectively (fig. 2F). Metatarsal IV exceeds II slightly in distal extent and plantar deflection. Fossa metatarsi I is not strongly demarcated but rather developed as a broad, shallow concavity (fig. 2A).

\section{PHYLOGENETIC ANALYSES}

Analyses of two datasets (Mayr and Clarke, 2003 for Aves; Livezey, 1998 for

middle Eocene Irdin Manha Formation: (A) AMNH 2936, the Eogrus aeola holotype specimen, (B) AMNH 2937, referred to Eogrus aeola and figured in Wetmore (1934). Wetmore (1934) figured the distal tarsometatarsus of an Eogrus aeola referred specimen (AMNH 2937; fig. 3B, $5 \mathrm{~B}, 6 \mathrm{C}$, this paper) and not the holotype specimen (Wetmore, 1934: fig. 2). In the holotype specimen (AMNH 2936) the metatarsal IV trochlea was broken and improperly reattached (figs. 3A, 5A, 6A). Anatomical abbreviations: pvf proximal vascular foramen, rap reattachment point of broken distal metatarsal II, tct tibialis cranialis tubercles. 


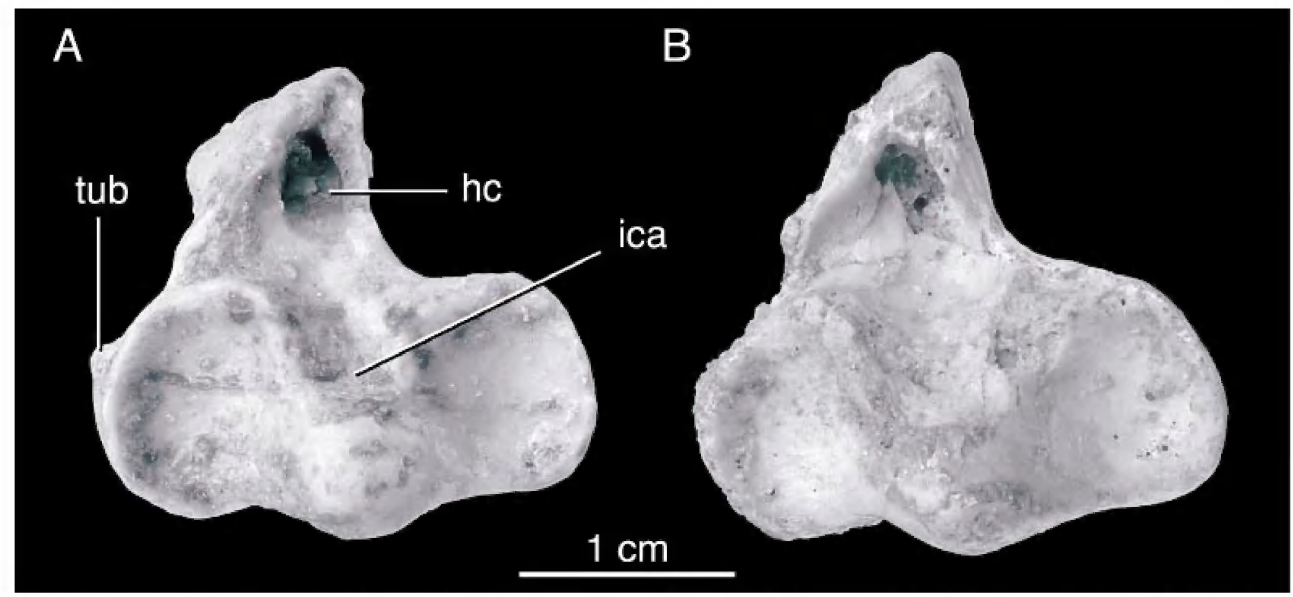

Fig. 4. Proximal ends of the right tarsometatarsi comprising (A) the holotype, AMNH 2936, and (B) a referred specimen, AMNH 2937, of Eogrus aeola in proximal view. Anatomical abbreviations: hc hypotarsal canal, ica intercotylar area, tub muscular tubercle.

Grues) investigated the systematic position of the new fossil and Eogruidae. The more completely known Eogrus aeola was used as an exemplar for Eogruidae in these analyses. The Eogrus aeola terminal was scored from AMNH 2936, the Eogrus aeola holotype specimen, as well as from AMNH 2937 and AMNH 2946, referred to Eogrus aeola. Character entries for this terminal in the two datasets were identical to that for the new fossil, IGM 100/1447 (and to the Eogrus wetmorei holotype, AMNH 2949), for all scored characters in common (appendix 1). The metatarsal II trochlea characters present in IGM 100/1447, and Eogruidae more broadly (see Systematic Paleontology), were unique among the taxa sampled. As such, they would not have been uninformative for, and were not included in, the phylogenetic analyses.

Seven characters from Mayr and Clarke (2003) could be evaluated for the new fossil (see appendix 1) while these and an additional two tibiotarsal characters could be scored for Eogrus aeola. Analysis of the complete Mayr and Clarke (2003) dataset with the Eogrus aeola terminal was performed using PAUP*4.08b (Swofford, 2002) and the same heuristic search parameters as in the primary analysis of the original publication: 1000 replicates of random stepwise addition (branch swapping: tree-bisection-reconnection) were performed holding only one tree at each step. No more than 10 trees one step longer than the shortest were retained in each replicate. Branches were collapsed to create polytomies if the minimum branch length was equal to zero. With the same settings as in the primary analysis, 1000 bootstrap replicates were also performed.

Three most parsimonious topologies resulted (Length: 819, CI: 0.33, RI: 0.48, RC: 0.16). The strict consensus cladogram of these trees recovered a Psophiidae + Eogrus aeola + Gruidae clade (fig. 9). Six unambiguously optimized synapomorphies supported this clade in all three most parsimonious trees (i.e., 36:1 otic process of quadrate with a cluster of small pneumatic openings, 56:1 notarium present, 71:2 sternum with 7-8 sternal rib articular surfaces, 72:1 dorsal surface of sternum with numerous pneumatic foramina, 73:1, caudal margin of sternum with two notches/fenestrae, 102:1 distal rim of medal condyle of tibiotarsus notched) although this clade was not recovered in greater than $50 \%$ of the bootstrap replicates. Character 102:1, the presence of a notch in the medial condyle of the distal tibiotarsus, is the only one of these unambiguously optimized synapomorphies preserved in Eogrus aeola. 


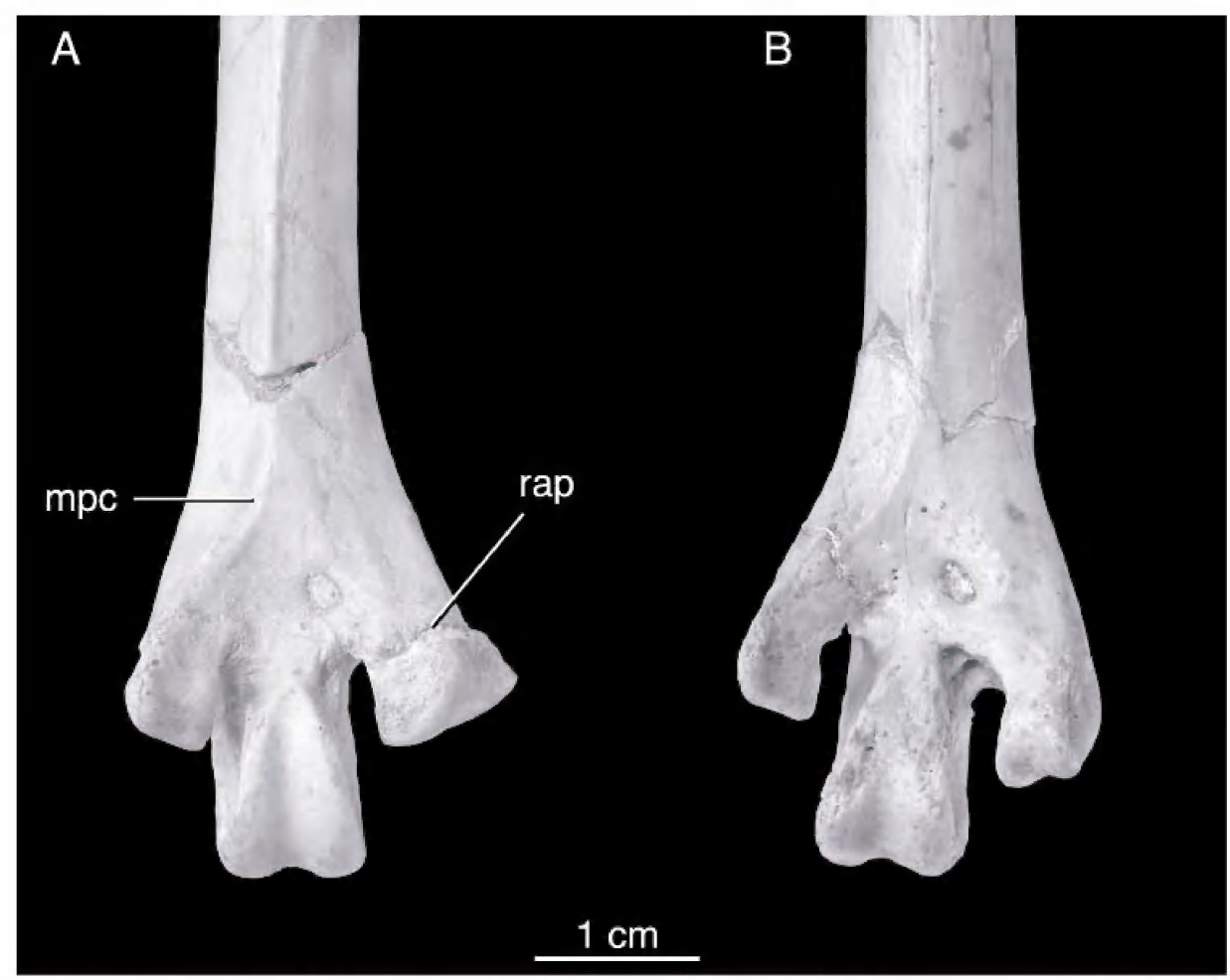

Fig. 5. Distal ends of the right tarsometatarsi comprising (A) the holotype, AMNH 2936, and (B) a referred specimen, AMNH 2937, of Eogrus aeola in plantar view. Anatomical abbreviations: mpc medial plantar crest, rap reattachment point of broken distal metatarsal II.

The Livezey (1998) Grues dataset with the addition of the Eogrus aeola terminal and the new fossil was then analyzed using PAUP*4.08b (Swofford, 2002). Twenty-four characters from Livezey (1998) could be evaluated for the new fossil (see appendix 1) while these and nine additional tibiotarsal characters could be scored for Eogrus aeola. The suborder Grues dataset of Livezey (1998) was modified to exclude detailed reconsideration of Ralloidea interrelationships. Six taxa placed as parts of the basal three divergences within Ralloidea were included (of the 204 Ralloidea sampled in Livezey,

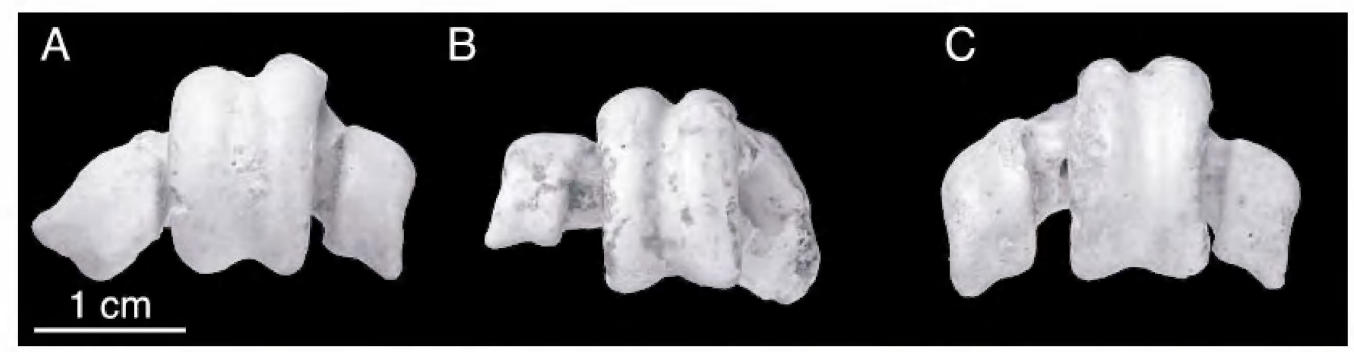

Fig. 6. Tarsometatarsi of the (A) holotype specimen of Eogrus aeola, AMNH 2936 (right side), and referred specimens (B) AMNH 2946 (left side), and (C) AMNH 2937 (right side) in distal view. 


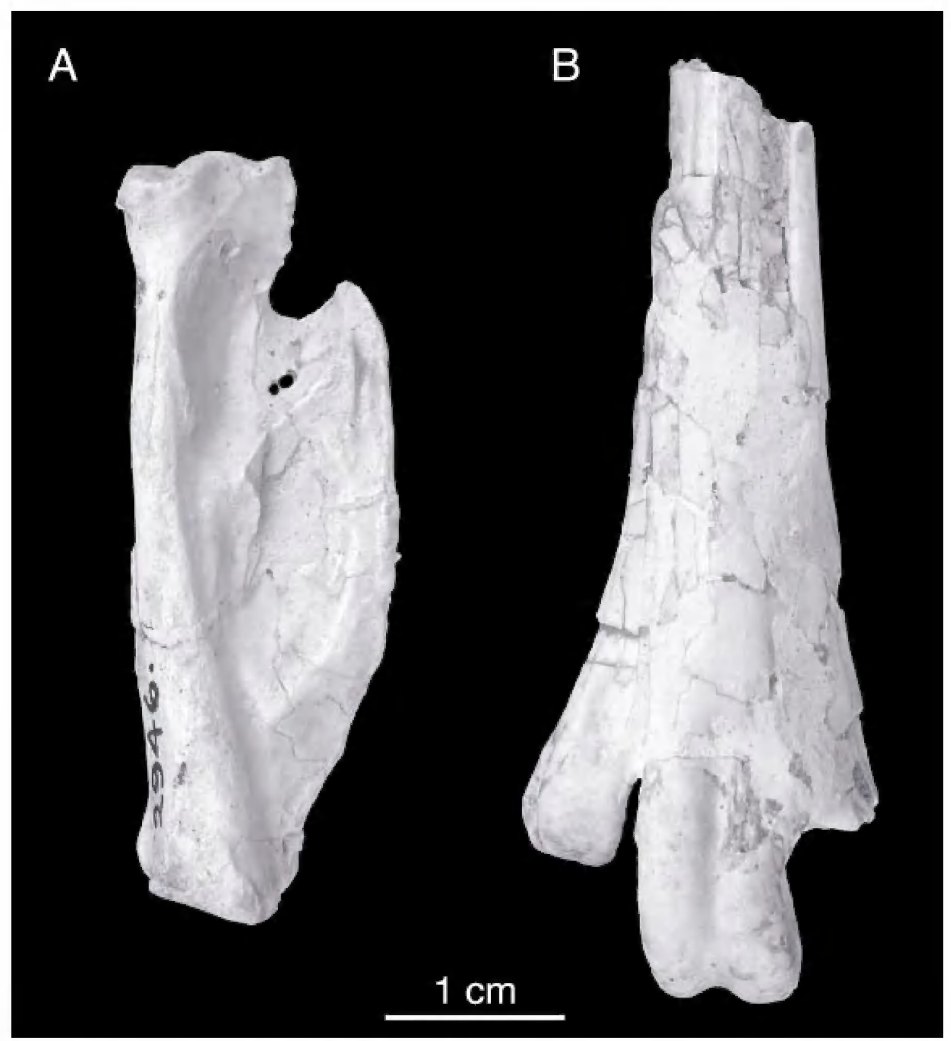

Fig. 7. The (A) left manual phalanx II:1 in ventral view and (B) left distal tarsometatarsus in dorsal view of AMNH 2946, a specimen (or possibly specimen "lot"; see Wetmore, 1934: 9) referred to Eogrus aeola and collected from Camp Margetts, Shara Murun region, Irdin Manha Formation in 1930.

1998) to represent this clade (i.e., Heliopais personata, Podica senegalis, Heliornis fulica, Himantornis haematopus, Gymnocrex rosenbergii, and Gymnocrex plumbeiventris; Livezey, 1998: fig. 1).

The 26 ingroup terminals and the one outgroup, "Ancestor 2" of Livezey (1998), were first analyzed in a branch and bound search including IGM 100/1447. Branches were collapsed to create polytomies if the minimum branch length was equal to zero. Of the 570 characters in the Grues dataset (Livezey, 1998), 205 were parsimony informative (21 of which were specified as ordered per Livezey, 1998) for the reduced number of included taxa. Eight most parsimonious trees (Length: 340, CI: 0.74, RI: 0.91, RC: 0.67) resulted. A strict consensus cladogram of these trees recovered IGM 100/
1447 as part of Gruoidea (sensu Livezey, 1998; this paper, fig. 10). One character placed IGM 100/1447 closer to an Aramidae + Gruidae clade than to Psophiidae (353:0, trochlea metatarsi II subequal to IV in distal projection, distal end reaching approximately middle of trochlea metatarsi IV; fig. 10), and the plesiomorphic states for two characters place the new fossil outside Aramidae + Gruidae clade (351:0 trochlea metatarsi II "eminentia plantaris" [Livezey, 1998], or lateroplantar wing, moderately developed rather than conspicuously enlarged [fig. 2A, F]; and 352:0 plantar extent of trochlea metatarsi II less than that of trochlea metatarsi IV [fig. 2F]). Monophyly of Gruidae is supported by 12 optimized synapomorphies $(59: 1,103: 4$, 155:1, 224:1, 234:1, 258:0, 325:1, 341:1, 371:2, 476:1, 487:2, 533:2). 1000 bootstrap 


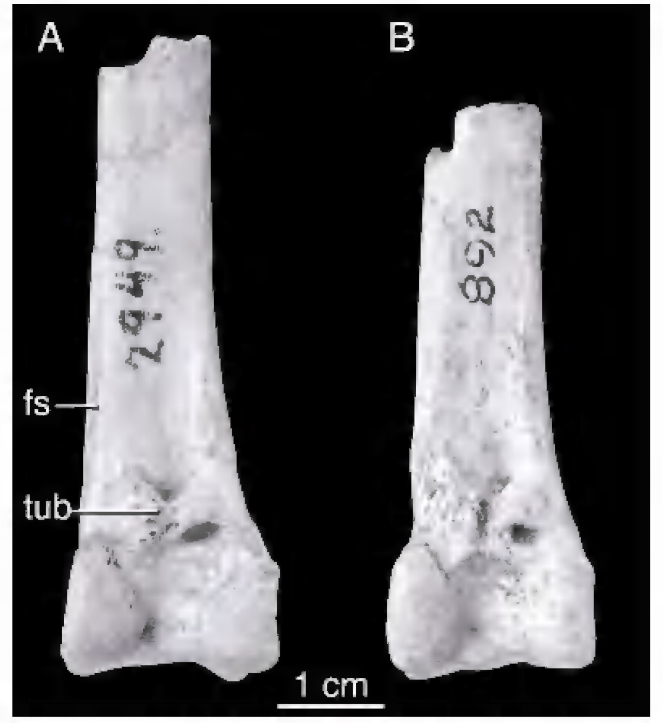

Fig. 8. Distal tibiotarsi of (A) AMNH 2949, the Eogrus wetmorei holotype specimen (Brodkorb, 1967) in anterior view and (B) AMNH 2946 (see figs. 6B, 7), referred to Eogrus aeola (Wetmore, 1934). The Eogrus wetmorei holotype (Brodkorb, 1967) was collected from Wolf Camp, 40 miles southeast of Iren Dabasu, Shara Murun region, from the Miocene Tunggur Formation. Anatomical abbreviations: fs flexor sulcus; tub preserved base of muscular tubercle referenced by characters 321 of Livezey (1998) and 101 of Mayr and Clarke (2003).

replicates were also performed with the same settings as in the primary analysis (fig. 10).

Analysis of this dataset including the Eogrus aeola terminal also resulted in eight most parsimonious trees with a placement for that taxon identical to that of IGM 100/1447 but one step longer (Length: 341, CI: 0.74, RI: 0.91, RC: 0.67). Including both the Eogrus aeola and IGM 100/1447 terminals in a single analysis would result in operationally redundant terminal taxa because they are identical for all scored characters in common (as mentioned above).

Unfortunately, the hypothetical ancestor outgroup specified for the Grues dataset using a larger analysis of Gruiformes (i.e., Ancestor 2 of Livezey, 1998) may not be appropriate as gruiform monophyly has been repeatedly questioned and was not supported in some recent analyses (Mayr and Clarke,
2003, and literature cited therein). Further, Rallidae was supported as the sister taxon to a Psophiidae + Eogrus aeola + Gruidae clade in the reanalysis of the Mayr and Clarke (2003) dataset in only two of the three most parsimonious trees, while another traditional gruiform taxon, Otidae, was supported as its sister in the third. Although gruiform monophyly generally, and the position of Rallidae, specifically, may be supported by future analyses, it was important to consider the effect of these contested assumptions about Gruoidea outgroups on the placement of Eogruidae.

The modified Grues dataset was reanalyzed excluding both Livezey's Ancestor 2 outgroup and Ralloidea (leaving 118 parsimony informative characters and 21 taxa). The same position of Eogrus aeola and IGM $100 / 1447$ was recovered in the strict consensus cladogram of the four resultant most parsimonious trees (Length: 172, CI: 0.82, RI: 0.92 , RC: 0.75 and Length: 173, CI: 0.82, RI: 0.92 , RC: 0.75 respectively). Thus, the inferred phylogenetic position of Eogruidae, as represented from IGM 100/1447 or Eogrus aeola, is robust to both the increased missing data in the new fossil (appendix 1) and to removing several assumptions about the position of Grues in Aves and relative to other parts of traditional gruiforms.

Six of the thirty-five distal tibiotarsal and tarsometatarsal characters potentially able to be evaluated for Eogruidae (i.e., characters $321-330,332-356$ ) were identified as diagnostic apomorphies of Grues subclades because they had a CI of 1.0 (Livezey, 1998: table 3; characters $321,324,325,327,341$, 354). The presence of an enlarged medially placed tubercle on the anterior surface of the distal tibiotarsus, character 321:1, was identified as a diagnostic synapomorphy of Gruoidea (Psophiidae + Aramidae + Gruidae; Livezey, 1998) and appears equivalent with character 101:1 of Mayr and Clarke, (2003), the presence of a large tubercle located laterally adjacent to the distal end of the ossified supratendinal bridge of the tibiotarsus. In Mayr and Clarke (2003) character 101:1 optimized as a synapomorphy of Psophiidae + Gruidae clade.

This tubercle is present in both Eogrus aeola and Eogrus wetmorei, although its tip 
is broken in the Eogrus wetmorei holotype specimen (fig. 8A), and it is not well preserved in some material referred to Eogrus aeola (e.g., fig. 8B). It is conspicuous in illustrations of Ergilornis sp. (e.g., Kurochkin, 1981: pl. 12), Amphipelargus (= Urmiornis, e.g., Kurochkin, 1981: pl. 15), as well as Sonogrus gregalis (e.g., Kurochkin, 1981: pls. 6-7). It has the same optimization (i.e., as a synapomorphy of Gruoidea) in the reanalyses of the Grues dataset (Livezey, 1998) and a consistent optimization in one of the three resultant trees from reanalysis of the Mayr and Clarke (2003) dataset. In the latter reanalysis, it was optimized as a synapomorphy of Gruidae + Psophiidae + Eogrus aeola only in the one most parsimonious topology where Rallidae was not placed as the sister taxon of this clade; Rallidae is polymorphic for this character (Mayr and Clarke, 2003).

Character state 324:1 (i.e., anterior face of the tibiotarsus flat or slightly concave for much of its length) was recognized as a diagnostic apomorphy of the clade Gruidae + Aramidae (Livezey, 1998). By contrast, 327: 1 (i.e., tuberositas retinaculi m. fibularis prominent, typically ossified anteriorly to form a bridge or arch) and 354:1 (i.e., metatarsal II trochlea with a groove extending to its dorsal surface) were identified as diagnostic apomorphies of Ralloidea (Livezey, 1998). Eogrus aeola is missing data for that character (324:1) optimized for Gruidae + Aramidae and lacks these two derived morphologies identified as diagnostic for Ralloidea. Of these characters, only 354 could be evaluated in the new fossil, which also lacks the derived condition present in Ralloidea (appendix 1).

Characters 325:1 and 341:1 were optimized as diagnostic apomorphies of Gruidae in Livezey (1998: table 3). Eogrus aeola and Eogrus wetmorei have the derived gruid condition for one of these two characters, 325: 1 , which describes a distal notch in the lateral condyle of the tibiotarsus (Livezey, 1998). However, this character was ambiguously optimized in the analyses including Eogrus aeola because of the outgroup position of this taxa relative to an Aramidae + Gruidae clade. This tibiotarsal character (325) could not be evaluated for IGM 100/1447, and thus
TABLE 1

Measurements of IGM 100/1447 and the Eogrus aeola Holotype, AMNH 2936 (in mm)

\begin{tabular}{lrc}
\hline \hline & IGM & \\
& 100/ & AMNH \\
\multicolumn{1}{c}{ Tarsometatarsus } & 1447 & 2936 \\
\hline Maximum length & 200.0 & 221.5 \\
Maximum proximal width & 23.4 & 21.0 \\
Maximum proximal dorsoplantar & & \\
$\quad$ dimension & 21.5 & 20.2 \\
Plantar projection medial hypotarsal & & \\
$\quad$ crest & 8.0 & 8.5 \\
Hypotarsus maximum width & 10.1 & 9.0 \\
Maximum distal width & 20.3 & $21.5^{*}$ \\
Metatarsal II trochlea width & 4.0 & 4.7 \\
Metatarsal III trochlea width & 10.0 & 8.8 \\
Metatarsal IV trochlea width & 6.5 & 6.2 \\
\hline
\end{tabular}

* Estimated: broken and reattached metatarsal II trochlea exaggerates width.

unambiguously optimizes as a synapomorphy of Gruidae in the reanalysis including only that terminal (fig. 10). Character 341 describes the distal extent of the medial parahypotarsal fossa relative to the hypotarsus, which is significant in the new fossil and Eogrus aeola. Reduction in distal extent (341:1) is unambiguously optimized as a synapomorphy of Gruidae in both the analysis including Eogrus aeola and that including IGM 100/1447 (fig. 10).

\section{DISCUSSION}

The IGM 100/1447 differs from the holotype specimen of Eogrus aeola and referred specimens in being less gracile (compare fig. 2 and 3-5). It is shorter (200.0 mm; table 1) than this element in Eogrus aeola, even given the significant length variation reported for this taxon (e.g., 221-244 mm, Wetmore, 1934). Reported infraspecific variation for Rallidae and Gruidae is considerable, and in several species identified as related fossil taxa (i.e., Bathornis celeripes and Elaphrocnemus phasianus), such variation was greatest for measurements of the tarsometatarsus (Cracraft, 1973). Sexual dimorphism in size was manifest as a $17 \%$ difference in proximal tarsometatarsus width in Grus grus (Stewart, 1999, in Göhlich, 2003) and varied from 9-19\% for total tarsometatarsus length in two rail species (Cracraft, 
1973). The difference between IGM 100/ 1447 and the largest measured specimen of Eogrus aeola (Wetmore, 1934) is $18 \%$ of the latter specimen. In Eogrus aeola, also by contrast to IGM $100 / 1447$, the dorsal tarsometatarsal surface is more concave than flat (fig. 3A), and the metatarsal III trochlea is relatively narrower (compare fig. $2 \mathrm{C}$, F with figs. 3-5).

The new specimen shares three more proportional features with the just younger Sonogrus gregalis (late Eocene; as illustrated in Kurochkin, 1981: pls. 4, 5) than it shares with the slightly older Eogrus aeola (middle Eocene; Russell and Zhai, 1987): the comparatively greater lateral projection of distal metatarsal IV and narrower breadth of the metatarsal III trochlea just commented on above (compare Kurochkin, 1981: pl. 5 and our fig. $2 \mathrm{C}$ to our fig. $3 \mathrm{C}$ ), as well as more angular rather than somewhat round tarsometatarsal cotylae outlines (compare Kurochkin, 1981: pl. 4 and our fig. $2 \mathrm{E}$ to our fig. 4).

The dorsoplantar diameter of the metatarsal II trochlea is slightly greater in IGM 100/ 1447 (fig. 2F) than in either Sonogrus gregalis (Kurochkin, 1981: pl. 5) or Eogrus aeola (fig. 6). The latter morphology, if infraspecific variation were investigated and ruled out as an explanation of difference, could be used (with the combination of other morphologies discussed) to differentiate a new species of Eogruidae with IGM 100/1447 as its holotype specimen. However, given the considerable infraspecific variation in related taxa (Cracraft, 1973; Stewart, 1999 in Göhlich, 2003); the reported presence of two distinct size classes of eogruids at Ergilin Dzo, and the difficulty of sorting isolated remains into distinct ergilornithid and eogruid species inferred present in a given locality (Kurochkin, 1976), we do can not rule out this explanation of the morphological differences noted. We also do not identify IGM 100/ 1447 as a new species because anagenetic change cannot be ruled out as an explanation of difference (e.g., Eogrus aeola, IGM 100/ 1447, and Sonogrus gregalis are each present in a distinct parts of the Eocene and Oligocene). Finally, barring inclusive restudy of variation in size and morphology across the abundant and poorly known Eogruidae taxa and broad taxonomic revision, designating the element described here as a new species would most likely simply add to future taxonomic complexity.

\section{CONCLUSIONS}

The phylogenetic analyses presented here are the first to address the systematic position of a significant part of early Tertiary Asian faunas (e.g., Wetmore, 1934; Kurochkin, 1976; Feduccia, 1999). Placement of Eogruidae as the sister taxon to an Aramidae + Gruidae clade is robust to changing outgroup assumptions and to swapping in the more incompletely known IGM 100/1447 as an exemplar for Eogruidae. The structure of these analyses may serve as a useful case study of the possible methods for the treatment of the isolated bones that comprise the majority of the avian fossil record: generally, it is necessary to utilize available datasets but take into account the limited consensus regarding crown clade avian deep divergences. Analyses should first investigate placement within Aves and then proceed to interrelationships of a particular subclade. If the fossil in question is referable by a previously described synapomorphy to a particular subclade, such broader scale analyses should be used to inform outgroup choice. It is further suggested not only to consider the resultant phylogenetic placement but also to track the hierarchical signal that supports the new fossil placement within a series of inter-nested clades, (e.g., Aves, Gruoidea; Phylogenetic Analyses, figs. 9,10). For example, placement of a specimen with synapomorphies of Aves, Neognathae, Neoaves and further internested subclades is the basis for a more strongly supported hypothesis than a specimen with an equal number of synapomorphies optimized at a single derived subclade node (Clarke, 2002, 2004). Because of the small amount of preserved character data in isolated bones like IGM 100/1447, it is crucial to utilize any additional information, like the structure of this character support, to inform the strength of their hypothesized placement.

Eogruidae (including Ergilornithidae) has been the object of much commentary concerning a proposed diversification of large 


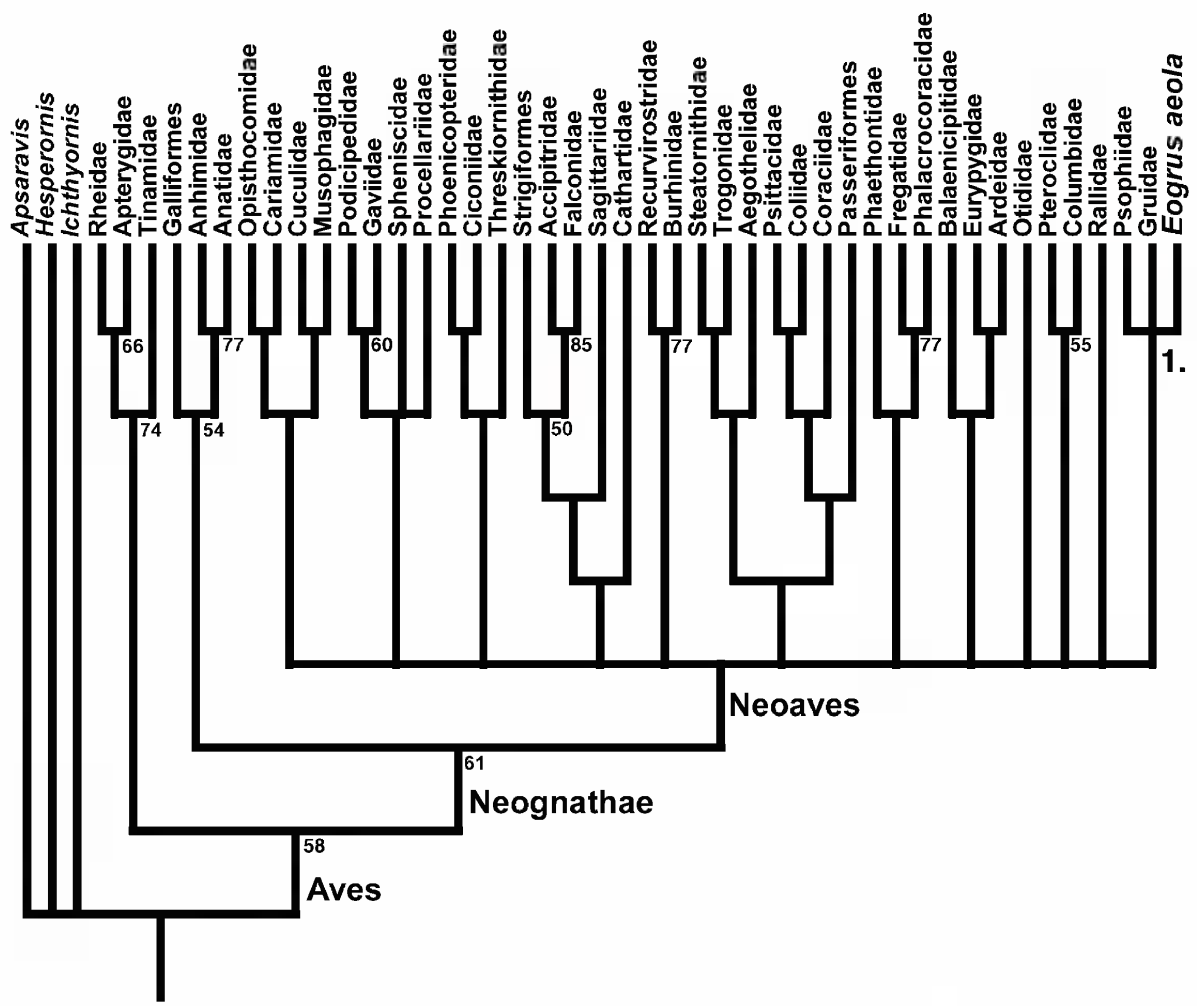

Fig. 9. A strict consensus cladogram of the three most parsimonious trees (Length: 819, CI: 0.33, RI: 0.48, RC: 0.16) from an analysis including Eogrus aeola in the modified Mayr and Clarke (2003) dataset. Characters unambiguously optimized as synapomorphies of a clade including Gruidae, Psophiidae, and Eogrus aeola in all most parsimonious trees are listed next to the corresponding node with the form "character:state": Aves $(1: 1,100: 1,107: 0 *)$, Neognathae $(20: 1,22: 1,29: 1,32: 1,79: 1,81: 1$, 94:1), Neoaves $(15: 1,16: 1,23: 1,93: 1)$, Node 1. $\approx$ Gruoidea $\left(36: 1,56: 1,71: 2,72: 1,73: 1,102: 1^{*}\right)$. Character numbers reference Mayr and Clarke (2003) and those derived states followed by an asterisk (*) are preserved in IGM 100/1447. Bootstrap support values greater than $50 \%$ are given below and to the right of the nodes to which they refer.

flightless avian cursors in the early Tertiary (e.g., Feduccia, 1999). It was suggested they were ancestors of the didactylous Ostrich (Struthio camelus) by those workers considering extant ratite birds polyphyletic (e.g., Olson, 1985). However, reduction in metatarsal II was regarded as clearly convergent on the Ostrich condition by others (e.g., Wetmore, 1934). Support from the present phylogenetic analyses for placement of the eogruid/ergilornithid lineage within a monophyletic Gruoidea when taken with support from abundant other previously published molecular and morphological data (e.g., Cracraft et al., 2004; Fain and Houde, 2004 and citations therein) for placement of Struthionidae within a monophyletic Palaeognathae indicates the evolution of a didactylous foot twice within the extant avian radiation; it is convergently present in ostriches and the Ergilornithidae.

Wetmore (1934) compared the cursorial "raptors" of the Cariamidae (Seriemas) to Eogrus aeola in their long and slender legs. From these features, he concluded that their habits could also have been similar (Wetmore, 1934). Reduction in the trochlea of metatarsals II and IV was taken to indicate that Eogrus aeola was more adapted to running than Cariamidae and that Eogrus aeola 


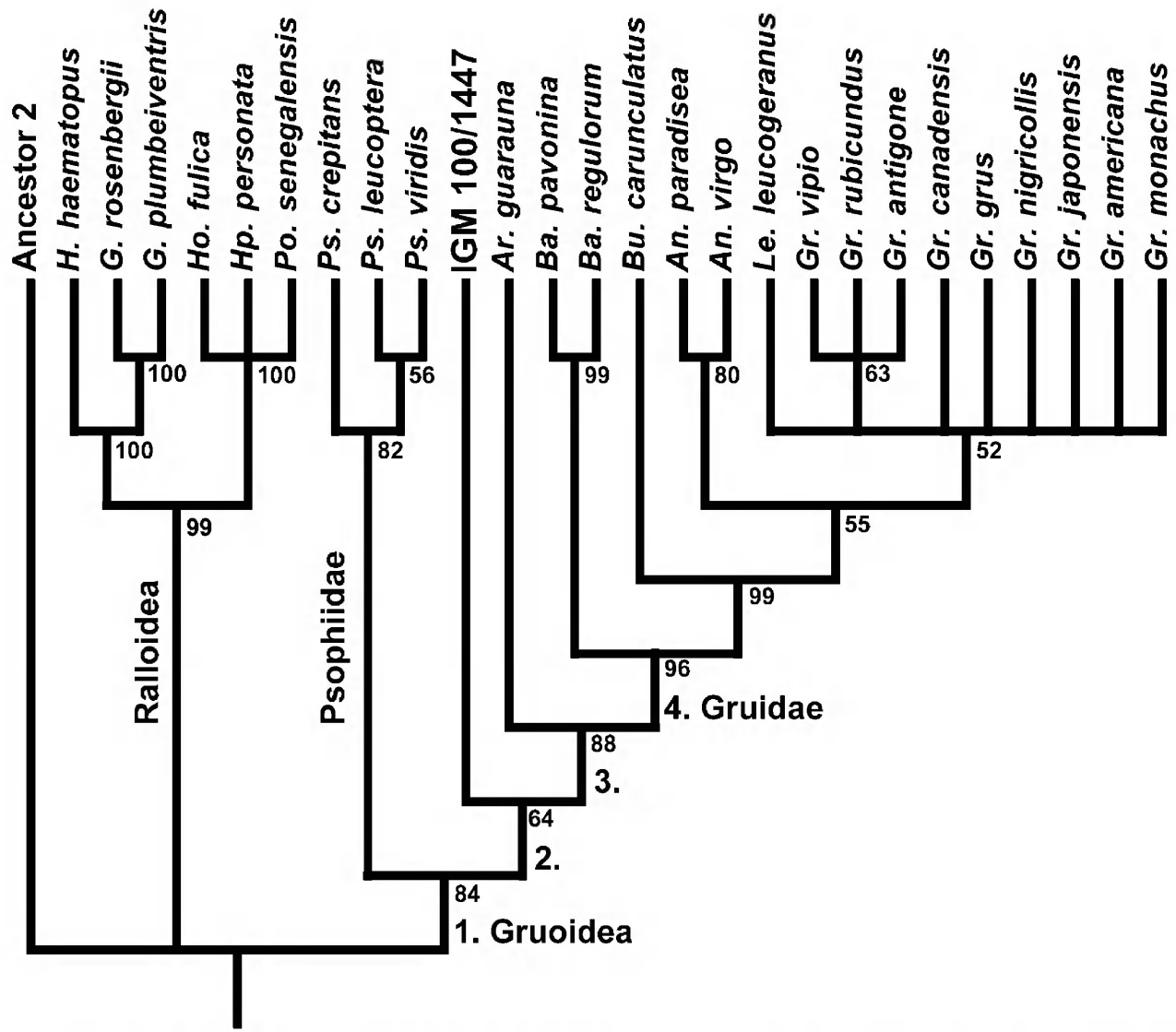

Fig. 10. A strict consensus cladogram of the eight most parsimonious trees (Length: 340, CI 0.74, RI 0.91, RC 0.67) from an analysis including IGM 100/1447 in the modified Livezey (1998) Grues dataset. Characters unambiguously optimized as synapomorphies of a clade are listed next to the corresponding node with the form "character:state": Node 1: Gruoidea (32:2, 89:1, 114:2, 115:1, 116:1, 134:1, 137:1, 202:1, 242:1, 272:1, 321:1, 366:1, 531:1), Node $2(353: 0 *)$, Node $3(351: 1 \dagger, 352: 1 \dagger)$, Node 4: Gruidae $(59: 1,103: 4,155: 1,224: 1,234: 1,258: 0,325: 1 \dagger, 341: 1 \uparrow, 371: 2,476: 1,487: 2,533: 2)$. Character numbers reference Livezey (1998). Those derived states followed by an asterisk (*) are preserved in IGM 100/1447, and those followed by a dagger ( $\dagger$ ) could be evaluated but IGM 100/1447 had the plesiomorphic condition.

must also have had a weakened power of flight (Wetmore, 1934: 11). Consistent with this hypothesis is one proximal humerus (PIN 3110-60 identified as "Ergilornithidae indeterminate" of Kurochkin, 1976 and Ergilornis minor? of Kurochkin, 1981) reported from the Oligocene Ergilin Member (Ergilin Dzo Formation) of Khoer Dzan with the reduced deltopectoral crest and pronounced ventral tubercle found in other flightless avian taxa.
The manual phalanx II:1 of a specimen referred to Eogrus aeola (fig. 7A) and possibly associated (see Wetmore, 1934) with a distal tarsometatarsus (fig. 7B) and tibiotarsus (fig. $8 \mathrm{~A}$ ) is, however, nearly identical in morphology and relative size (contra Olson, 1985) to the same element in extant Gruidae (e.g., Balearica pavonina. Black-Crowned Crane; e.g., AMNH 10775), which do not exhibit reduced flight capabilities.

It has been hypothesized that Eogruidae 
crossed from North America into Asia via an Eocene land bridge (e.g., Feduccia, 1999). However, it is not necessary to infer that these taxa needed to walk into Asia. Significant reduction in flight ability, as well as a functionally didactylous foot, are only supported later in Oligocene Eogruidae (consistent with Kurochkin, 1982; contra Olson, 1985). Conflation of derived and basal parts of the radiation is undesirable.

\section{ACKNOWLEDGMENTS}

We would like to thank Ed Heck and Mick Ellison for preparing the figures. Discussion with or commentary on the manuscript by E. Kurochkin, Meng Jin, Xiaoming Wang, Ursula Göhlich, Joel Cracraft, and an anonymous reviewer greatly improved the manuscript. NSF ATOL 0228693 and funding from the Frick Fund of the American $\mathrm{Mu}$ seum of Natural History for this project is gratefully acknowledged.

\section{REFERENCES}

Bendukidze, O. 1971. Novyj prestavitel' semeistva Geranoididae (Aves, Gruiformes) iz eotsenovykh otlozhenij Zaisan. Soobtzhenija Akademii Nauk Gruzinskoj SSSR 63: 749-751.

Brodkorb, P. 1967. Catalogue of fossil birds, part 3 (Ralliformes, Ichthyornithiformes, Charadriiformes). Bulletin of Florida State Museum of Biological Science II 3: 1-220.

Cantino, P.D., and K. de Queiroz. 2000. PhyloCode: a phylogenetic code of biological nomenclature (online paper). Athens: Ohio University. (updated 3 May 2000). Available at www.ohiou.edu/phylocode/.

Clarke J.A. 2002. The morphology and taxonomy of Ichthyornis Marsh and the phylogenetic relationships of basal Ornithurae. Ph.D. dissertation, Yale University. New Haven, CT, 535 pp.

Clarke, J.A. 2004. Morphology, phylogenetic taxonomy, and systematics of Ichthyornis and Apatornis (Avialae: Ornithurae). Bulletin of the American Museum of Natural History 286: 1179.

Cracraft, J. 1969. Systematics and evolution of the Gruiformes (Class, Aves) 1. The Eocene family Geranoididaea and the early history of the Gruiformes. American Museum Novitates 2388: 1-41.

Cracraft, J. 1973. Systematics and evolution of the Gruiformes (Class Aves). 3. Phylogeny of suborder Grues. Bulletin of the American Museum of Natural History 151: 1-127.
Cracraft, J., F.K. Barker, M. Braun, J. Harshman, G.J. Dyke, J. Feinstein, S. Stanley, A. Cibois, P. Schikler, P. Beresford, J. García-Moreno, M.D. Sorenson, T. Yuri, and D.P. Mindell. 2004. Phylogenetic relationships among modern birds (Neornithes). In J. Cracraft and M.J. Donoghue (editors), Assembling the tree of life: 468-489. New York: Oxford University Press.

Dashzeveg, D. 1985. Nouveaux Hyaenodontinae (Creodonta, Mammalia) du Paléogene de Mongolie. Annales de Paléontologie 71: 223-256.

Dashzeveg, D. 1991. Hyracodontids and rhinocerotids (Mammalia, Perissodactyla, Rhinocerotoidea) from the Paleogene of Mongolia. Palaeovertebrata 21: 1-84.

Dashzeveg, D. 1993. Asynchronism of the main mammalian faunal events near the Eocene Oligocene boundary. Tertiary Research Special Papers 14: 141-149.

Dashzeveg, D. 1996a. A new Ardynomys (Rodentia, Cylindrodontidae) from the Eocene of the eastern Gobi Desert of Mongolia. Paleovertebrata 25: 339-348.

Dashzeveg, D. 1996b. Some carnivorous mammals from the Paleogene of the eastern Gobi Desert, Mongolia, and the application of Oligocene Carnivores to stratigraphic correlation. American Museum Novitates 3179: 1-14.

Dashzeveg, D., and E.B. Devyatkin. 1986. Eocene-Oligocene boundary in Mongolia. In C. Pomerol and Premoli-Silva (editors), Terminal Eocene events: developments in paleontology and stratigraphy, Amsterdam: Elsevier Science Publishers BV, 153-157.

de Queiroz, K., and J. Gauthier. 1992. Phylogenetic taxonomy. Annual Review of Ecology and Systematics 23: 449-480.

Fain, M., and P. Houde. 2004. Parallel radiations in the primary clades of birds. Evolution 58: 2258-2573.

Feduccia, A. 1999. The origin and evolution of birds, 2nd ed. New Haven, CT: Yale University Press, 466 pp.

Göhlich, U. 2003. A new crane (Aves: Gruidae) from the Miocene of Germany. Journal of Vertebrate Paleontology 23: 387-393.

Harrison, C.J. 1981. A reassignment of Amphipelargus majori from Ciconidae (Ciconiformes) to Ergilornithidae (Gruiformes). Tertiary Research 4: 53-69.

Karhu, A. 1997. A new species of Urmiornis (Gruiformes: Ergilornithidae) from the early Miocene of western Kazakhstan. Paleontological Journal 31: 102-107.

Kozlova, E.V. 1960. Novye iskopaemye ptitsy iz jugo-vostochnoj Gobi. Trudy Problemnogo i Tematicheskogo Soveshchaniya Zoologicheskij Institut A Akademie Nauk SSSR 9: 323-329. 
Kurochkin, E.N. 1976. A survey of the Paleogene birds of Asia. In S.L. Olson (editor), Collected papers in avian paleontology honoring 90th birthday of Alexander Wetmore. Smithsonian Contributions to Paleobiology 27: 75-86.

Kurochkin, E.N. 1981. New representatives and evolution of two archaic gruiform families in Eurasia. Trudy Sovmestnaja Sovetsko-Mongolskaja Paleontologicheskaja Ekspeditsija 15: 59-85.

Kurochkin, E.N. 1982. On the evolutionary pathways of didactylous Tertiary gruids under increasing aridization. In A. Novak and J. Milíkovsky (editors), Evolution and environment: 731-736. Prague: CSAV.

Livezey, B.C. 1998. A phylogenetic analysis of the Gruiformes (Aves) based on morphological characters, with an emphasis on the rails (Rallidae). Philosophical Transactions of the Royal Society (London) B 353: 2077-2151.

Livezey, B.C., and R.L. Zusi. 2001. Higher-order phylogenetics of modern Aves based on comparative anatomy. Netherlands Journal of Zoology 51(2): 179-205.

Mayr, G., and J. Clarke, 2003. The deep divergences of neornithine birds: a phylogenetic analysis of morphological characters. Cladistics 19: 527-553.

Olson, S.L. 1985. The fossil record of birds. In
D.S. Farner, J.R. King, and K.C. Parkes (editors), Avian biology, vol. VIII: 79-238. New York: Academic Press.

Radinsky, L. 1964. Notes on Eocene and Oligocene fossil localities in Inner Mongolia. American Museum Novitates 2180: 1-11.

Russell, D., and R. Zhai. 1987. The Paleogene of Asia: mammals and stratigraphy. Mémoires du Muséum National d'Histoire Naturalle Série C 52: 1-488.

Stewart, J. 1999. The evolution of Quaternary birds in the western Palaearctic: aspects of taxonomy and ecomorphology. Ph.D dissertation, University College London, London, 410 pp.

Strauch, J.G. 1978. The phylogeny of the Charadriiformes (Aves): a new estimate using the method of character compatibility analysis. Transactions of the Zoological Society of London 34: 263-345.

Swofford DL. 2002. PAUP* Phylogenetic analysis using parsimony (*and other methods). Version 4.0. Sinauer Associates, Sunderland.

Wang, X., Z. Qiu, and N.D. Opdyke. 2003. Litho-, bio-, and magnetostratigraphy and paleoenvironment of Tunggur Formation (middle Miocene) in central Inner Mongolia, China. American Museum Novitates 3411: 1-31.

Wetmore, A. 1934. Fossil birds from Mongolia and China. American Museum Novitates 711: $1-16$.

\section{APPENDIX 1}

SCORED CHARACTERS FOR IGM 100/1447, EOGRUS AEOLA AND EOGRUS WETMOREI

IGM 100/1447 scoring in Mayr and Clarke (2003) dataset: 103:1, 104:0, 105:1, 106:0, 107:0, 108:1, 109:0.

Eogrus aeola scoring in Mayr and Clarke (2003) dataset: 101:1; 102:1, 103:1, 104:0, 105:1, 106:0, 107:0, 108:1, 109:0.

Eogrus wetmorei scoring Mayr and Clarke (2003) dataset: 101:1; 102:1. IGM 100/1447 scoring in Livezey (1998): 332:?, 333:0, 334:0, 335: 0 , 336:0, 337:0, 338:0, 339:0, 340:0, 341:0, 342: $0,343: 0,344: 0,345: 0,346: 0,347: 0,348: 0,349$ : $0, \quad 350: 0, \quad 351: 0, \quad 352: 0, \quad 353: 0, \quad 354: 0, \quad 355: 0$ 356:0.
IGM 100/1447 scoring in Livezey (1998) dataset: $333: 0,334: 0,335: 0,336: 0,337: 0,338: 0$, $339: 0,340: 0,341: 0,342: 0,343: 0,344: 0,345: 0$, $346: 0,347: 0,348: 0,349: 0,350: 0,351: 0,352: 0$, 353:0, 354:0, 355:0 356:0.

Eogrus aeola scoring in Livezey (1998) dataset: $321: 1,322: 0,323: 0,324: ?, 325: 1,326: 0,327$ : 0, 328:0, 329:0, 330:0/1, 331:?, 332:?, 333:0, 334: 0, 335:0, 336:0, 337:0, 338:0, 339:0, 340:0, 341: $0,342: 0,343: 0,344: 0,345: 0,346: 0,347: 0,348:$ $0,349: 0,350: 0,351: 0,352: 0,353: 0,354: 0,355:$ 0 356:0 (91.3\% missing in Livezey [1998] Gruiformes dataset; $94.2 \%$ in Grues dataset).

Eogrus wetmorei scoring in Livezey (1998) dataset: 321:1, 322:0, 323:0, 324:?, 325:1, 326:0, 327:0, 328:0, 329:0, 330:0/1. 
Complete lists of all issues of the Novitates and the Bulletin are available at World Wide Web site http://library.amnh.org/pubs. Inquire about ordering printed copies via e-mail from scipubs@amnh.org or via standard mail from: American Museum of Natural History, LibraryScientific Publications, Central Park West at 79th St., New York, NY 10024. TEL: (212) 7695545. FAX: (212) 769-5009.

(2) This paper meets the requirements of ANSI/NISO Z39.48-1992 (Permanence of Paper). 